\title{
Observation of fast tropospheric dynamics and impacts on humidity and air pollution during a heatwave event in New York City, as observed by lidars, other profilers and surface measurements
}

\author{
Fred Moshary*, Adrian Diaz Fortich, Yonghua Wu, Mark Arend, Prathap Ramamurhty, and Barry \\ Gross \\ NOAA Center for Earth System Science and Remote Sensing Technology, The City College of New York, \\ New York, NY 10031, USA. \\ *Email: moshary@.ccny.cuny.edu
}

\begin{abstract}
Exposure to heatwaves in densely populated urban areas are of major health concern. Interaction of heatwaves with urban areas are complex; not only driven by mesoscale meteorology, but also by the topology and thermal properties of urban surfaces, as well as anthropogenic thermal and pollution loadings. The impact of heatwaves on population in coastal urban areas such as New York City depend on interplay of these factors as well as the effects of sea/land breeze. These mechanisms can lead to rapid changes in pollution levels and heat index during the day. High time resolution synergistic observations with surface and profiling measurements are needed to capture and understand these dynamics. We report on fast tropospheric dynamics during a heatwave in New York City in summer 2018, resulting in a transient event during which dramatic reduction of pollutants and humidity in the tropospheric column is observed by lidars and other synergistic measurements.
\end{abstract}

\section{INTRODUCTION}

The United Stated National Weather Service defines heatwaves as three consecutive days with temperature highs above $90 \mathrm{~F}(32 \mathrm{C})$. On the average, in US, heatwaves are the deadliest severe weather events [1] and the US Centers for Disease Control estimates that annually, over 600 people die of extreme heat related complications. While globally, there are different definitions for heatwaves, the health impacts of heatwaves are of major concern across different communities. As a consequence of climate change, the frequency and intensity of heatwaves are expected to increase, representing a major threat to populations. This is especially exacerbated in urban areas, where surface roughness (urban topology), and thermal properties of surfaces (e.g. surface thermal potential and impervious surfaces) can lead to further elevated temperatures due to the Urban Heat Island effect [2]. Increasingly, air conditioning is used to alleviate the impact of heatwaves in private and public spaces, which can create further adverse effects in densely populated urban areas by increasing the heat load on the urban atmosphere [3]. Increased use of air conditioning also leads to increased electric demand. In certain cities like New York, this peak electricity demand is met by peaking generation plants within the city, leading to increased urban emissions. The combination of increased emissions together with ample heat and sunshine leads to efficient photochemical production of pollutants such as ozone and secondary aerosols (PM2.5), resulting in pollution exposure at levels exceeding the National Ambient Air Quality Standards (NAAQS) and posing additional health concerns for urban and downwind communities .

Convection driven turbulence and other related tropospheric dynamics during heatwaves can drive densities and fluxes of water vapor and other trace gases and particulates, and as such affect their impacts. We report on observation made during a heatwave episode in New York City during the multi-agency Long Island Sound Tropospheric Ozone Study (LISTOS) campaign in the Summer 2018. The specific episode lasted from June $29^{\text {th }}$ to July $3^{\text {rd }}$. During the heatwave, ozone levels exceeded the NAAQS ( $8 \mathrm{hr} 70 \mathrm{ppb}$ ) for June 30 to July $2^{\text {nd }}$ where peak temperatures observed reached about 35 degrees each day. PM2.5 levels exceeding $35 \mu \mathrm{g} / \mathrm{m}^{3}$ were observed but the $24 \mathrm{hr}$ fine particulate matter NAAQS was not exceeded.

In this period of time, an extensive suite of surface 
analyzers including measurement of meteorological parameters and trace gases, as well as column profiling instruments such as visible and microwave radiometers, and aerosol and wind lidars were deployed to characterize the surface and atmospheric conditions. During the day-time high temperature periods, fast and anomalous dynamics in atmospheric column concentrations of particulates and trace gases were observed and are presented in this report. Preliminary analysis suggest that these are due to free-troposphereboundary layer exchanges and clear air subsidence.

\section{METHODOLOGY}

At CCNY-campus in northern Manhattan, NYC, a suite of ground-based remote sensing instruments are deployed on a building roof, which include: a 3-wavelength elastic-Raman lidar, a ceilometer (Vaisala CL51), a scanning mini-micropulse lidar (SigmaSpace mini-MPL) a scanning Doppler wind lidar (Leosphere 200S), thermodynamic microwave profiling radiometer (Radiometrics MP300A), and a CIMEL sun/sky radiometer (part of NASA AERONET). In addition, the New York State Department of Environment Conservation (NYSDEC) operates a sampling facility with $\mathrm{O}_{3}$, $\mathrm{CO}$, and $\mathrm{PM}_{2.5}$ analyzers on the CCNY campus. Finally, a Campbell Scientific weather station measures surface level meteorological conditions.

\section{OBSERVATIONS}

Figure 1 shows the ceilometer observations of the boundary layer aerosol profiles during June 30 .

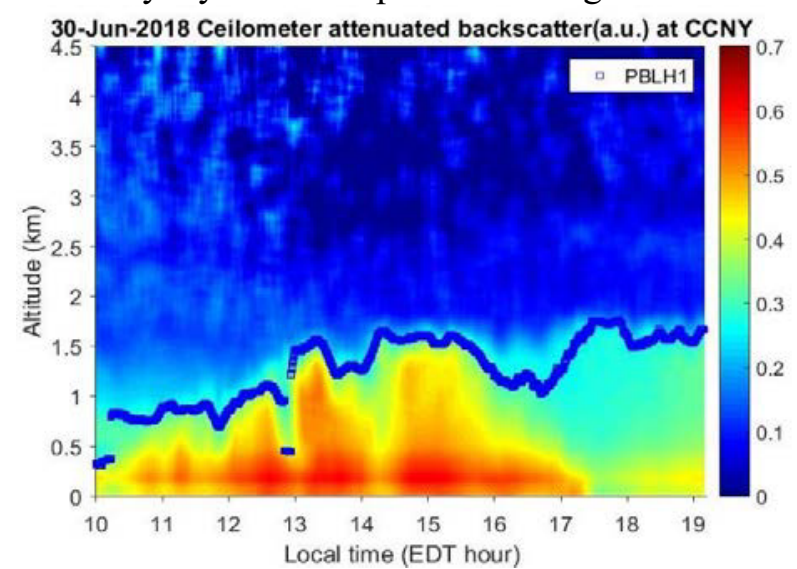

Fig. 1 Aerosol profiles observed by a Vaisala CL31 ceilometer on June 30.

During the daytime hours as the temperature increases, large pronounced oscillation in aerosol concentration within the boundary layer is observed. These features were also seen by the CCNY multiwaveleght lidar system and the observations were consistent with the similarly rapid changes in surface PM2.5 concentration and column aerosol optical depth as observed by NASA AERONET CIMEL instrument.

Later on during the heatwave on July $2^{\text {nd }}$, a more dramatic feature is observed during midday as shown in figure 2 This figure shows the ceilometer profile of aerosols within the boundary layer aat high time resolution to capture the rapid changes.

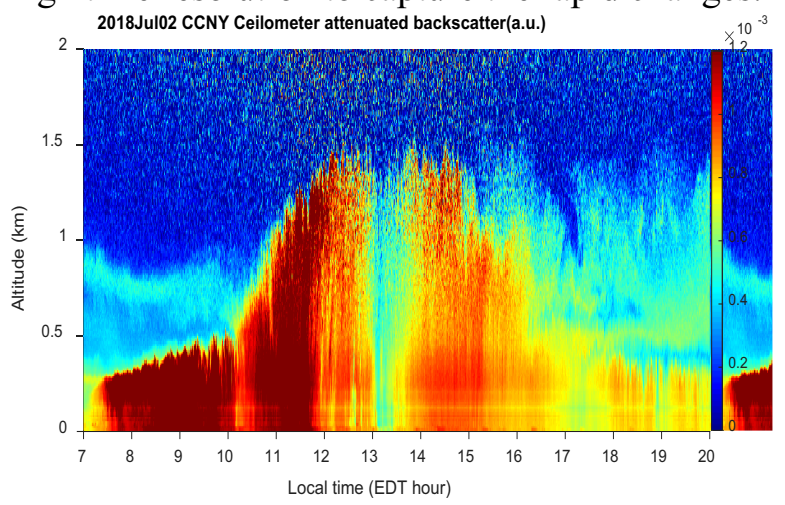

Fig. 2 Ceilometer aerosol profiles on July 2 .

As can be seen from this figure, at approximately 1 pm local time, the atmospheric column clears all the way to the surface for about $1 \mathrm{hr}$. We particularly note the sharp features observed here. Again the same feature is observed by the multiwavelength lidar.

Figure 3 shows the observed column optical depth consistent with the profiling observations.

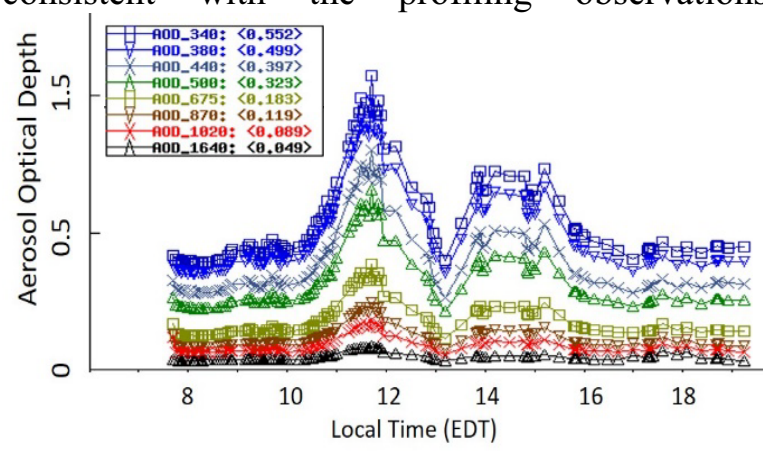

Fig. 3. AERONET AOD observations for July 12, 2018.

The near air temperature and humidity are shown in Figure $4 \mathrm{a}$ and $\mathrm{b}$. As the temperature climbs to 
its maximum of $35 \mathrm{C}$ by $1 \mathrm{pm}$, there is a noticeable notch in the relative humidity at this time coincident with the clearing observed by the lidars.
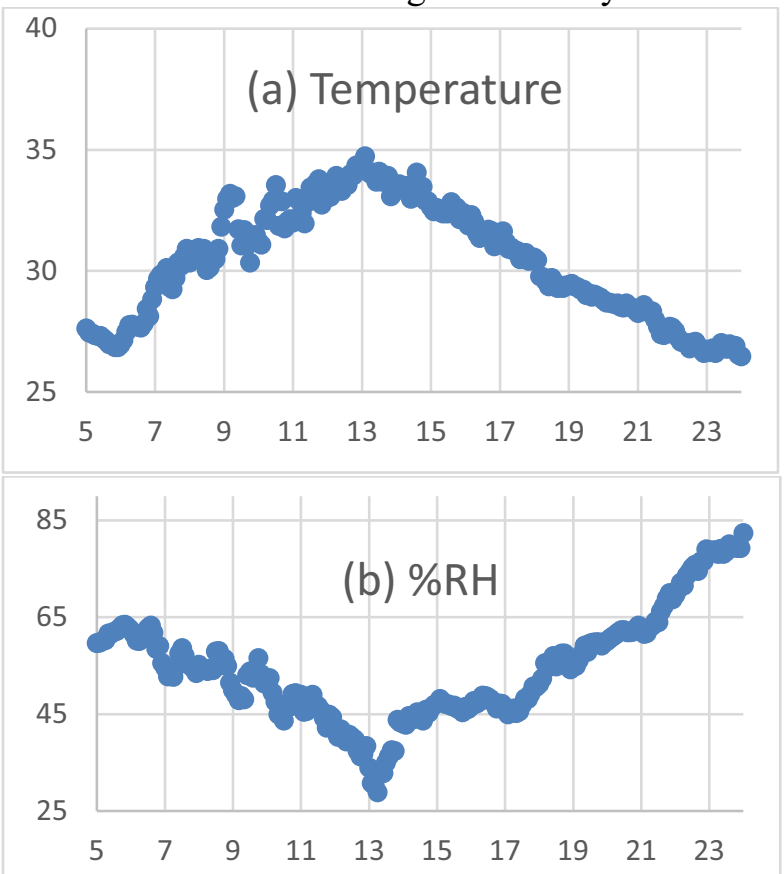

Fig 4. (a) Near surface air temperature and (b) near surface humidity measured for July 2, 2018.

Similarly, the microwave radiometer measurements of the column humidity profiler shows that the column dries out during this same event with dramatic decrease in relative humidity all the way to the surface as can be seen in figure 5 .

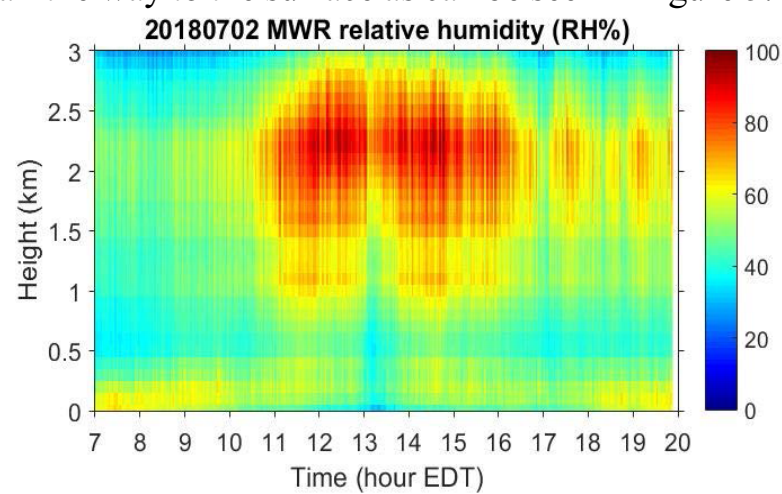

Fig 5. Microwave profiler observations of RH for July 2.

Figure 6a shows the surface PM2.5 measurement and $5 \mathrm{~b}$ the surface ozone measurements for this day. At 11:30 am the PM2.5 concentration exceeds 40 $\mu \mathrm{g} / \mathrm{m}^{3}$ but by $13: 30$ the level have dropped to $3 \mu \mathrm{g} / \mathrm{m}^{3}$. The surface ozone also exhibits a decrease from $117 \mathrm{ppb}$ to $78 \mathrm{ppb}$.
The surface wind conditions in the morning leading up to the observed event are light and variable. The horizontal wind profiles measured with a wind lidar are consistent as seen in figures 7 .

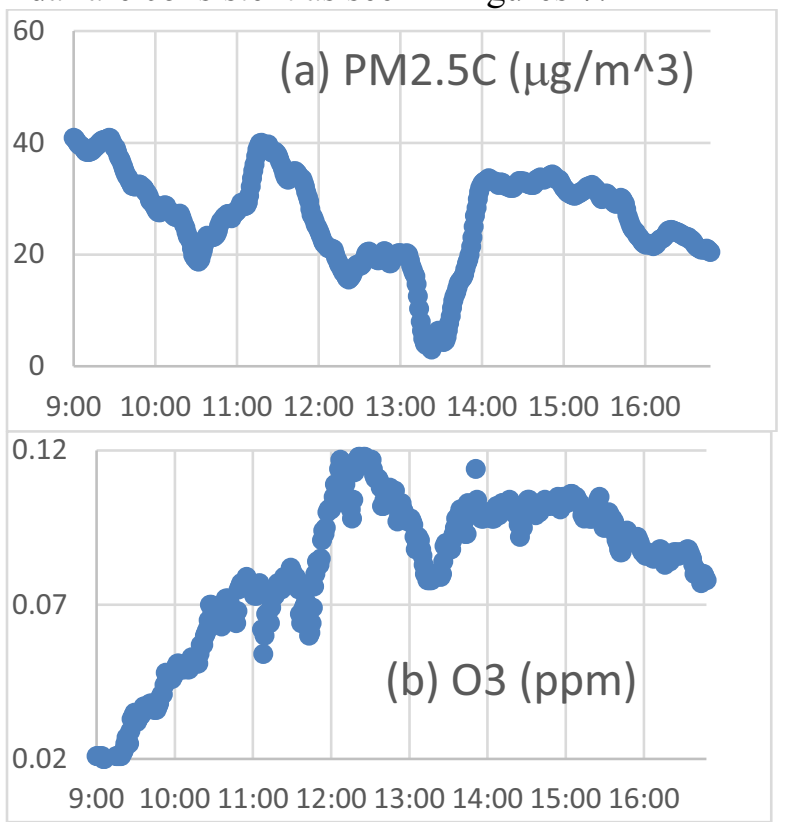

Fig 6 (a) PM 2.5 and (b) Ozone concentrations
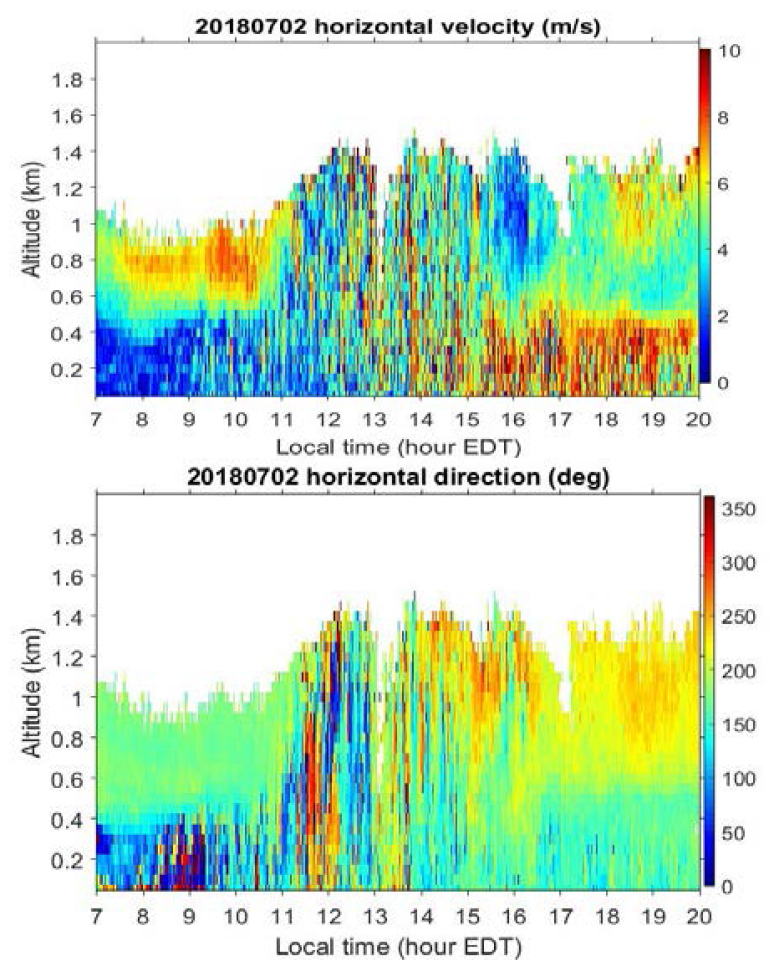

Fig. 7 (a) Horizontal wind speed and (b) Wind direction measured by LEOSPHERE 200S wind lidar.

During morning hours, we observe a low level jet from the south at 400-900 meter before $11 \mathrm{am}$. 
After this time, the winds are variable for the next 5 hours across the entire column. At about $2 \mathrm{pm}$, southerly near-surface winds evolve up to a 500 meter above which the winds are southwesterly to $1.2 \mathrm{~km}$ height. These are consistent with surface wind observations. The afternoon winds appear to gradually clear the atmospheric after about $3 \mathrm{pm}$ consistent with ceilometer and surface observation.

However, there is clear evidence of a dramatic updraft preceding the clearing of the atmospheric column at $1 \mathrm{pm}$.as can be seen in figure 8 .

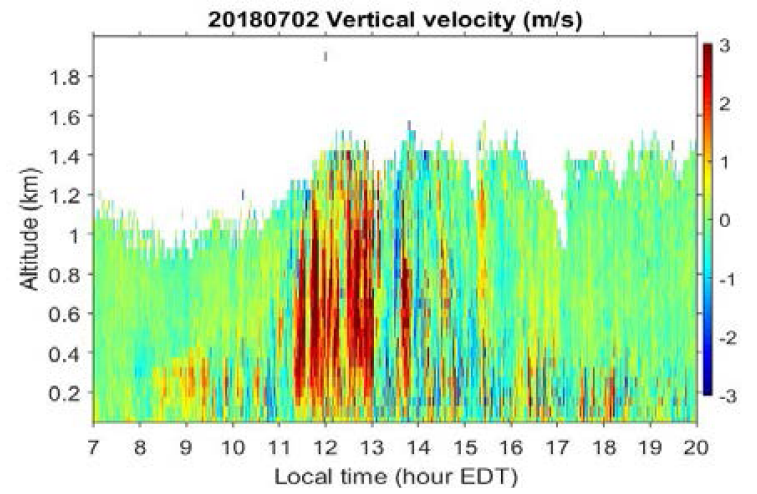

Fig. 8 Vertical winds measured by wind ldiar on July 2 .

The strong updraft event lasts nearly $1.5 \mathrm{hrs}$ staring at 11:30, during which time the mixing layer height grows to $1.5 \mathrm{~km}$. However, the updraft event abruptly ends at $1 \mathrm{pm}$. After $1 \mathrm{pm}$, there is a turbulent period with both updrafts and down drafts, but these are reltatively short lived.

The observed event is limited in spatial extent. Observations from the horizontally scanning micropulse lidar pointed eastward at 100 meter elevation shows that the clearing extends at least $3.5 \mathrm{~km}$ east. Other lidar observations in the region show that the event is observed up to $7 \mathrm{~km}$ northeast of the CCNY, however it is not as dramatic at that distance. However, the event is not observed $14 \mathrm{~km}$ to the southeast or $20 \mathrm{~km}$ to the south, still within the boroughs of New York City.

\section{DISCUSSIONS AND CONCLUSION}

During a five day heatwave event in NYC, which lead to exceedance of ozone NAAQS, we report observation of rapid changes of aerosols and trace gase concentrations within the boundary layer column. The case of June $30^{\text {th }}$ shows several oscillation while the case of July $2^{\text {nd }}$ shows a single dramatic event that lasts for about $1 \mathrm{hr}$. These events seem to come about with sharp transitions on the order of minute. The July $2^{\text {nd }}$ case is extensively studied with data presented from a number of ground-based analyzers and atmospheric column and profiling remote sensing instruments. Horizontal wind observations at the surface and above are not suggestive of transport being the reason for the observed clearing. However, as can be seen from figure 5, the event extends above the mixing layer all the way to about $3 \mathrm{~km}$, ushering in dry air into the atmospheric column. This observation is suggestive of exchange with the free troposphere with clear air subsidence into the planetary boundary layer. Vertical wind profiles show some evidence of downdraft following $1 \mathrm{pm}$, however, not as dramatic as the updraft observed prior to the clearing of the atmospheric column. The column stays clear for about $1 \mathrm{hr}$, after which, the concentrations of water vapor and other trace constituents rapidly recover. The onset of horizontal winds after $3 \mathrm{pm}$ gradually clears the boundary layer, while the air temperatures cool into the evening. Based on remote sensing measurements spatial extent of the observed events is on the order of several kilometers. The dynamics observed, on the order of $1 \mathrm{hr}$ or less on both June 30 and July 2 show that high time resolution is needed to capture these transients, while groundbased remote sensing probes the vertical and horizontal scale of the vent.

ACKNOWLEDGEMENTS. This study is supported by the New York State Energy Resources Development Authority (grant \# 100415), NESCAUM (project \#2411) and the NOAA CESSRST under the NOAA Agreement NA16SEC4810008.

\section{REFERENCES}

[1] https://www.nws.noaa.gov/om/hazstats.shtml

[2] Prathap Ramamurthy, Jorge Gonzalez, Luis Uriarte, Mark Arend, Fred Moshary, Impact of heatwave on a megacity: an observational analysis of New York City during July 2016, Environmental Research Letters 12, 54011 (May 2017).

[3] Xiaoyu Xu, Fei Chen, Shuanghe Shen, Shiguang Miao, Michael Barlage, Wenli Guo and Alex Mahalov, Using WRF-Urban to Assess Summertime Air Conditioning Electric Loads and Their Impacts on Urban Weather in Beijing, the J. Geophysical Res.: Atmospheres, 123, 5, (2475-2490), (2018). 